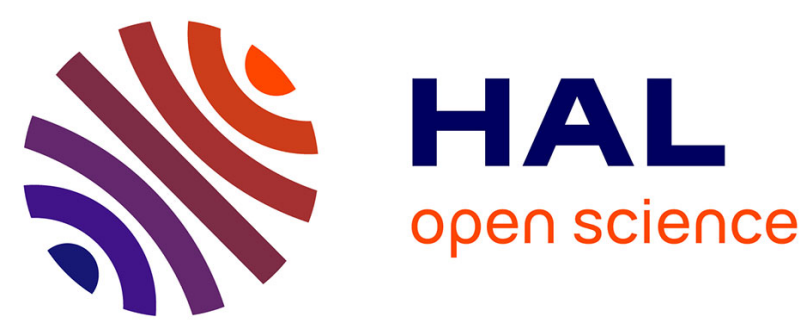

\title{
Newborn right-holding is related to depressive symptoms in bottle-feeding mothers but not in breastfeeding mothers
}

\author{
Julien Donnot, Jacques Vauclair, Vincent Bréjard
}

\section{- To cite this version:}

Julien Donnot, Jacques Vauclair, Vincent Bréjard. Newborn right-holding is related to depressive symptoms in bottle-feeding mothers but not in breastfeeding mothers. Infant Behavior and Development, 2007, 10.1016/j.infbeh.2007.12.013 . hal-02087555

\section{HAL Id: hal-02087555 \\ https://hal-amu.archives-ouvertes.fr/hal-02087555}

Submitted on 2 Apr 2019

HAL is a multi-disciplinary open access archive for the deposit and dissemination of scientific research documents, whether they are published or not. The documents may come from teaching and research institutions in France or abroad, or from public or private research centers.
L'archive ouverte pluridisciplinaire HAL, est destinée au dépôt et à la diffusion de documents scientifiques de niveau recherche, publiés ou non, émanant des établissements d'enseignement et de recherche français ou étrangers, des laboratoires publics ou privés. 


\title{
Newborn right-holding is related to depressive symptoms in bottle-feeding mothers but not in breastfeeding mothers
}

\author{
Julien Donnot ${ }^{\mathrm{a}, *}$, Jacques Vauclair ${ }^{\mathrm{a}}$, Vincent Bréjard ${ }^{\mathrm{b}}$ \\ a Centre for Research in Psychology of Cognition, Language and Emotion (Centre PsyCLE), University of Provence, \\ 29 Avenue R. Schuman, 13621 Aix-en-Provence Cedex 1, France \\ b Psychology of Education, Cognition and Development Laboratory (LabECD), University of Nantes, \\ Chemin la Censive du Tertre BP 81227, 44312 Nantes Cedex 3, France
}

Received 28 August 2007; received in revised form 9 November 2007; accepted 27 December 2007

\begin{abstract}
This study examines the relationships between infant holding preferences and maternal depression according to the newborn feeding mode. Links between depression and infant holding biases have been observed in mothers [Vauclair, J., Scola, C. (in press). Dépression, alexithymie et latéralisation dans la façon de porter un nouveau-né [Infant holding biases in relation to depression, alexithymia and laterality]. Annales Médico-psychologiques; Weatherill, R. P., Almerigi, J. B., Levendosky, A. A., Bogat, G. A., von Eye, A., \& Harris, L. J. (2004). Is maternal depression related to side of infant holding? International Journal of Behavioral Development, 28, 421-427] but the fact that breastfeeding has never been studied in relation to these two factors is surprising as breastfeeding has some influence on depression (e.g., [Mezzacappa, E. S., Guethlein, W., Vaz, N., \& Bagiella, E. (2000). A preliminary study of breast-feeding and maternal symptomatology. Annals of Behavioral Medicine, 22, 71-79]) and must also affect holding biases. Mothers who just gave birth $(N=100)$ were tested few days after delivery. Measures of handedness, infant holding-side preferences, and level of depressive symptoms expressed by mothers (assessed with the CES-D scale) were collected via questionnaires. Asymmetries in emotional perception were assessed via a Chimeric Figure Task and a Dichotic Listening Task. Results showed that breastfeeding (1) reduced left-side bias for holding newborns and (2) was associated with lowest levels of depressive symptoms. Moreover, holding biases were related to maternal depression in bottle-feeding but not in breastfeeding mothers, namely that holding on the right-side while bottle-feeding was associated with higher levels of depressive symptoms. These results were not due to hemispheric specialization as auditory and visual asymmetries were similar between breastfeeding and bottle-feeding mothers. The discussion emphasizes the striking role of the early mother/child relationship's establishment on infant holding biases.
\end{abstract}

(C) 2008 Elsevier Inc. All rights reserved.

Keywords: Infant holding; Mother-child relationship; Maternal depression; Breastfeeding; Bottle-feeding; Laterality; Perception of emotions

\section{Introduction}

\subsection{Infant holding biases}

\subsubsection{Report and explanations of the left-side preference}

In the investigations focused on mother-child interactions, some specific behaviors, namely infant holding preferences, have drawn attention because of their predictive quality and influence on the establishment of the early

\footnotetext{
* Corresponding author. Tel.: +3344293 39 94; fax: +33442389170.

E-mail address: Julien.Donnot@univ-provence.fr (J. Donnot).
} 
mother-child relationship. Most of the human beings express a left-side preference for holding an infant in arms (e.g., Donnot \& Vauclair, 2005, in press for a review; Erber, Almerigi, Carbary \& Harris, 2002; Salk, 1960). This left bias does not concern exclusively women as studies found left holding side preferences in male participants (Bogren, 1984; Bundy, 1979; Harris, Almerigi, \& Kirsch, 2000) and even in 6 years old children (De Château \& Andersson, 1976; Manning \& Chamberlain, 1991). The robustness of this left bias was demonstrated by different experimental procedures which all concluded in left holding side preferences (imagination task: Harris, Almerigi, Carbary, \& Fogel, 2001; life-size neonatal doll: e.g., Manning \& Chamberlain, 1991; photographic survey: Harris \& Fitzgerald, 1985; questionnaires: Donnot \& Vauclair, 2007; World Wide Web survey: Harris, Spradlin, \& Almerigi, 2006).

Thinking that the left holding bias has a unique cause is bound to fail if we consider the evidence provided by recent studies (Van der Meer \& Husby, 2006; Vauclair \& Donnot, 2005; Weatherill et al., 2004). Weatherill et al. (2004) tested the role of depression and observed that non-depressed mothers significantly held on the left-side, whereas depressed mothers tended to held on the right-side. A study by Vauclair and Scola (2008) confirmed the existence of a link between infant holding side preferences and the psychological state (depression and alexithymia) of the mother but only with males newborns. Recently, Suter, Huggenberger, \& Schäehinger, 2007) showed that the use of a stressful bilateral cold pressor test reduced left cradling in female volunteers tested with a baby-like doll. Reissland, Hopkins, Helms, and Williams (in press) specified that stress, more than depression reduced the left-side bias in mothers. Harris et al. (2001) but also Bourne and Todd (2004) and Vauclair and Donnot (2005) demonstrated the role of visual lateralized perception of emotions by showing correspondences between holding side preferences and visual field advantages for emotional perception in student populations. Donnot (2007) confirmed these results with auditory field advantages in a left-handed student population. Moreover, handedness can be a determining factor of functional cradling side preference. When participants had to hold a doll and simultaneously give a pacifier to this doll, they kept the dominant hand free, whichever their handedness (Van der Meer \& Husby, 2006).

We support the view of a multifactorial determination for infant holding side preferences (for a review see Donnot \& Vauclair, in press). These preferences could result from the combination of lateralized perception of emotion, handedness and mother's psychological state (e.g., the presence of depressive symptoms). The detection of the influence of these factors is difficult to assess because they vary as a function of the holder's characteristics and/or of the holding context (environmental features and reasons why the infant is held). Donnot and Vauclair (2007) distinguished two holding relationships according to the quality of interactions in the dyad (i.e., a student holding a doll is an example of a basic holding relationship and a mother holding her newborn is a example of an advanced holding relationship). The handedness hypothesis can be questioned because infant right-holding biases have never been reported in left-handers (e.g., Donnot, 2007; Manning \& Chamberlain, 1991), except if the holding situation requires the use of a skilled hand to interact with the newborn (Van der Meer \& Husby, 2006). The role of the emotional perceptive asymmetry can also be questioned as Donnot and Vauclair (2007) did not confirm this hypothesis with new mothers (advanced relationship) studied in maternity hospitals.

\subsubsection{The infant left-holding theory}

The main question about infant holding side is to know if one side is more advantageous for the infant and/or the holder. Considering the results reported in the studies cited above, we can advance that left-side holding presents more advantages than right-side holding for the majority of people. The reasons are that (1) the right-hand is kept free to interact with the infant and/or the environment, (2) emotional stimuli are better perceived in the left visual and auditory fields, and (3) newborns prefer to turn their head to the right (Ginsburg, Fling, Hope, Musgrove, \& Andrews, 1979). Obviously some people do not take advantages of all these characteristics, namely left-handers, people who better perceive emotions in the right field or parents of newborns with left head-turning preference. It is quite difficult to develop a left-holding theory as the choice of the infant holding side certainly depends on several variables, but also seems to depend on the affective relationship established between the holder and the newborn. Thus, the relations between right-holding and depression could be confirmed in some cases, but right-holding must not be systematically considered as disadvantageous compared to left-holding.

\subsubsection{The measure of infant holding-side biases}

The majority of the studies on infant holding biases focused on the side of holding but an extensive knowledge of infant holding behavior implies distinguishing two main observed holding styles and, above all, requires a consideration of the holding contexts. Vauclair and Donnot (2005) differentiated arm-holding, which represented the more frequently 
chosen holding style, from shoulder-holding. Starting from this distinction, infant holders may express either a holding side preference common to both styles (e.g., left arm-holding and left shoulder-holding), or infant holders may express side preferences which differ for holding styles (e.g., left arm-holding and right shoulder-holding). Consequently, a categorization of left- or right-holders may be radically different according to the holding style observed. Moreover, the nature of the mother-child interactions can also vary according to these styles. Arm-holding allows for visual and auditory communication between the mother and her newborn, whereas visual interactions are strictly limited in shoulder-holding for the benefit of tactile interactions. It seems important to us to consider the holding side for each holding style and the preferred holding style to collect a more precise measure of infant holding preferences. We are interested in holding biases that concern emotional interactions between the mother and her newborn (e.g., soothing context). To that purpose, we recorded direct holdings and responses to a holding questionnaire. For two reasons we decided to use a questionnaire for data analyses. Firstly, there was an overall congruence between observed (via direct observation) and reported (via the questionnaire) holding side biases. Secondly, the data collected via the questionnaire were more adapted to data analyses because scores take into account frequency of holding styles. In addition, as the mothers spent most of their time in bed, the use of the questionnaire allowed us to assess infant holding in other contexts than holding the newborn in bed.

\subsection{Newborn feeding mode}

\subsubsection{Breastfeeding and mother-child relationship}

The present study focused on the most relevant population for investigating infant holding, namely mothers, and aimed at defining which characteristics of the mothers are linked to the holding biases and to the presence of possible depressive symptoms. Feeding the newborn obviously represents one of the first opportunities of interactions between the mother and her newborn.

Advantages of breastfeeding on mother-child relationship have been demonstrated in several studies. Dunn and Richards (1977) have noted that breastfeeding mothers tend to touch, cradle and smile to their babies more than bottlefeeding mothers both at the first and at the eighth week. Kuzela, Stifter, and Worobey (1990) but also Wiesenfeld, Malatesta, Whitman, Grangose, and Uili (1985) have shown that breastfeeding mothers expressed more feeling emotional closeness to their infants and tended to have more infant- and familycentered attitudes. The mothers who nursed reported a greater desire to pick up or hold their infants than bottle-feeding mothers (Wiesenfeld et al., 1985). Women who intended to breastfeed were more satisfied with the shape of their body and had higher levels of maternal fetal attachment. Body shape dissatisfaction and low maternal fetal attachment may account for why some women choose to bottle-feed (Foster, Slade, \& Wilson, 1996). Obviously breastfeeding is the best newborn's feeding mode, but some mothers cannot breastfeed or decide to bottle-feed their newborn. Maternal depression can also lead mothers to avoid breastfeeding.

\subsubsection{Newborn feeding mode and depressive symptoms}

One of the most important advantages of breastfeeding is that it protects against maternal depression. Some studies have demonstrated that breastfeeding mothers (a) were less stressed and anxious than bottle-feeders and (b) thought that, by breastfeeding, their infants would feel more secure and bonded to them (Heck \& De Castro, 1993; Mezzacappa, Guethlein, Vaz, \& Bagiella, 2000). Depressed women reported more negative attitudes towards breastfeeding and had more difficulties with breastfeeding in the postpartum period than did non-depressed mothers (Tamminen, 1988). Moreover depressed women choose less often to breastfeed or did so for relatively short periods of time than nondepressed women (Field, Diego, \& Hernandez-Reif, 2006 for a review; Field, Hernandez-Reif, \& Feijo, 2002; Galler, Harrison, Biggs, Ramsey, \& Forde, 1999) and depressed mothers who had stable breastfeeding patterns were less likely to have infants with highly reactive temperaments (Jones, McFall, \& Diego, 2004).

\subsection{The present study}

The role of hemispheric specialization on infant holding biases has been demonstrated in several studies (Bourne \& Todd, 2004; Donnot, 2007; Harris et al., 2001; Vauclair \& Donnot, 2005) but exclusively in students' populations and never in mothers' populations. Donnot and Vauclair (2007) concluded that the basic holding relationship, because of the small number of intervening factors, may present favorable conditions to express the influence of hemispheric 
specialization on holding biases. By contrast, in an advanced relationship (e.g., a mother with her newborn) many affective and environmental factors intervene in the determination of holding biases. In this context, it is likely that the role of hemispheric specialization will be reduced (Donnot \& Vauclair, 2007). The aim of this study is to ascertain if the newborn feeding-mode can be considered as a factor influencing infant holding preferences in an advanced relationship by investigating the links between infant holding biases and maternal depression. Bogren (1984) has reported that right-holding parents expressed more concerns about pregnancy and delivery compared to left-holders. Weatherill et al. (2004) and Vauclair and Scola (2008) showed that depressed mothers tended to hold their infant on the right-side. Given the fundamental role of breastfeeding in the construction of early mother-child relationship, it is necessary to determine the links between holding biases and depressive symptoms according to the newborn feeding mode.

It is likely that the feeding behavior has some influences on the holding behavior and then, that it can modify infant holding biases. Breastfeeding would lead mothers to often hold on the right-side for the well-being of their newborn. In fact, feeding the newborn with the right breast increases the comfort of the mother for holding on the right-side which can lead her to hold on the right with purposes other than breastfeeding (e.g., soothing, carrying). Bottle-feeding mothers would keep the dominant hand free (the right-hand for a large majority) to hold the bottle and then, they would not have opportunities to hold on the opposite side (the right-side for a large majority of mothers). Beyond the fact that bottle-feeding mothers should present a higher level of depressive symptoms and a stronger left infant holding bias, holding on the right should be less advantageous for these mothers than holding on the left, whereas breastfeeding mothers should not present such a difference.

\section{Methods}

\subsection{Participants}

Participants were 100 mothers who were tested a few days after delivery in two maternity hospitals (50 mothers were examined in each hospital). The mean age of the participants was 29.44 years (S.D. $=4.99)$. Forty-eight percent of the mothers were primiparous, $44 \%$ had given birth to their second offspring and $8 \%$ had given birth to their third offspring. Half of the observed newborns (49\%) were females. The mean birth weight was $3280 \mathrm{~g}$, with no sex difference $(t(98)=1.39, p=.17)$. Twelve percent of the mothers had a caesarean delivery. As concern the feeding mode, 59 of the mothers used breastfeeding and 41 used bottle-feeding.

On average, newborns were born 10 days sooner $($ S.D. $=12.5)$ than the expected term $(270$ days $)$ with, in the extreme cases, 49 days before ( $2 \%$ of the sample) and 21 days after (1\% of the sample). The newborns' age ranged from 1 to 6 days at the time of testing. Mothers who had delivered with a caesarean were always tested at least 3 days after their infant's birth, while mothers who had vaginal delivery were always tested between day 1 and day 3 after birth.

\subsection{Materials}

\subsubsection{Handedness and holding measures}

We used the inventory designed by Donnot and Vauclair (2007) to evaluate holding preferences and laterality. Handedness items were extracted from the Edinburgh Handedness Inventory (Oldfield, 1971). The degree of laterality was obtained by calculating a mean score on the ten-handedness items. A positive score indicates that the participant was right-handed and a negative one indicates that the participant was left-handed.

Holding preferences were measured in terms of preferred holding style (arm holding, shoulder holding, or no preference) and preferred holding side (left, right, or no preference). Mothers were shown the figures illustrating the two holding styles (see Fig. 1a and b). Holding preferences were assessed via the following question: "When you hold your newborn, how do you hold him/her?" Answers were given on a Likert scale: always shoulder holding, often shoulder holding, no preferred style, often arm holding, always arm holding. Arm holding was defined as holding the newborn horizontally in the arms. Shoulder holding was defined as holding the newborn vertically against the chest with the infant's head placed on the mother's shoulder (see Fig. 1a and b). Then the participants had to mention their preferred holding side (left or right) for each of the two holding styles (see Table 1).

Holding scores were calculated by considering side preferences for both holding styles. For example, a participant might hold on the left in arms and on the right on shoulder. If she preferred arm holding, her general preferred holding 

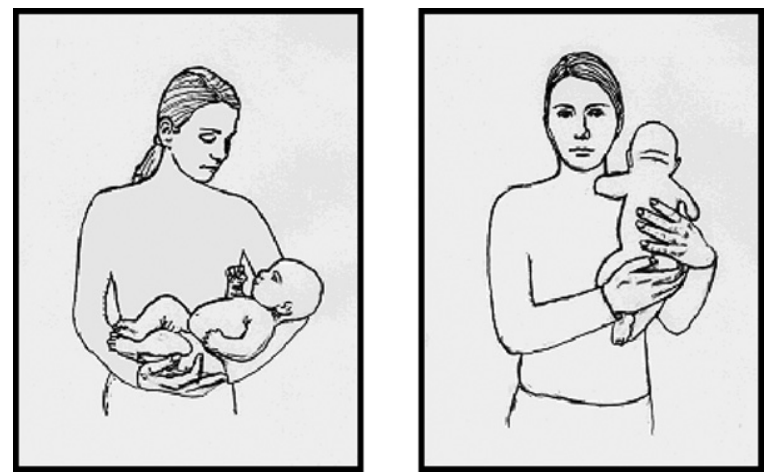

Fig. 1. Left arm-holding position and left shoulder-holding position.

Table 1

Holding preference question

When you hold your newborn, how do you hold her/him?

\begin{tabular}{|c|c|c|c|c|}
\hline $\begin{array}{l}\qquad \\
\text { Always } \\
\text { Shoulder holding }\end{array}$ & $\begin{array}{l}\square \\
\text { Often } \\
\text { Shoulder Holding }\end{array}$ & $\begin{array}{c}\square \\
\text { No preferred style }\end{array}$ & $\begin{array}{c}\square \\
\text { Often } \\
\text { arm holding }\end{array}$ & $\begin{array}{l}\square \\
\text { Always } \\
\text { arm holding }\end{array}$ \\
\hline \multirow{2}{*}{\multicolumn{3}{|c|}{$\begin{array}{l}\text { On which side do you prefer to hold her/him when arm holding? } \\
\text { On which side do you prefer to hold her/him when shoulder } \\
\text { holding? }\end{array}$}} & Left side $\square$ & Right side $\square$ \\
\hline & & & Left side $\square$ & Right side $\square$ \\
\hline
\end{tabular}

side was the left-side. A negative holding score indicated a general left-side preference and a positive score a general right-side preference.

\subsubsection{The CES-D scale}

This scale (Radloff, 1977), which is one of the most used in quantitative studies of depressive symptoms, has been validated in groups of French teenagers (Bailly, Beuscart, \& Collinet, 1992a, 1992b), and used with elderly people (e.g., Nubukpo, Hartmann, \& Clément, 2005; O'Rourke, 2003) but not in the normal French adult population. This is the reason why we carried out a preliminary study $(N=402)$ to compare the CES-D scale and the revised version of the Beck depression inventory (BDI-II: Beck, Steer, \& Brown, 1996). Results confirmed the excellent psychometric properties of the CES-D scale and a significant correlation between the two scales $(r(402)=.47, p<.001)$. Nevertheless, many participants have pointed out that the wording of some items of the BDI-II appeared as "shocking" (e.g., the item related to suicide). Mothers who just have given birth undergo a life period mixing up both happy events and difficulties. For that reason we preferred to use the CES-D scale, which appears to be more suited to study the general population and mothers in particular. Total CES-D scores range from 0 to 60 , with higher scores indicating higher levels of general depression. At the individual level, a score equal or higher than 16 is considered as a sign of depressive symptoms and a score above 22 is indicative of serious depressive symptoms. In the present study, the aim was not to determine if a group of participants was depressive or not, but to use the depression scale as a numerical variable to compare different groups of mothers. This is why we will give more importance to the differences between mean CES-D scores than to the mothers who reached the depression threshold (score of 16 and over).

\subsubsection{The dichotic listening task (DLT)}

Relations between left holding biases and asymmetrical emotional perception have been demonstrated only in nonparent participants (Donnot \& Vauclair, 2007). We assessed advantages for auditory and visual fields in emotional perception to test their relationships with holding biases. An emotional dichotic listening task used by Donnot (2007) and Donnot and Vauclair (2007) was used to assess auditory emotional asymmetries. Participants listened to five sentences in an imaginary language pronounced in two different emotional tones (among happy, angry and neutral), 
one to each ear. By example, the first sentence was pronounced in the angry tone to the left ear while the same sentence was pronounced in the happy tone to the right ear simultaneously. Each participant had to report the most clearly heard emotion for each of the 30 trials presented via headphones. A mean score was calculated for which a negative value indicates a left auditory field bias and a positive value indicates a right auditory field bias.

\subsubsection{The chimeric figures task (CFT)}

Visual emotional asymmetries were assessed with the use of a Chimeric Figures Task (e.g., Harris et al., 2001; Vauclair \& Donnot, 2005). On each trial, participants were shown two faces on a computer screen, one above the other for $5 \mathrm{~s}$. A face resulted from the combination of one smiling hemiface and one neutral hemiface. Each mother was individually tested and was requested to indicate orally the face that looked happier. Across the 30 trials, finding that the face was happier when the smile appeared on the left is assumed to reflect a greater right hemisphere role in the task. A mean score over all pictures was calculated for which a negative value indicates a left visual field bias and a positive value indicates a right visual field bias.

\subsection{Testing conditions}

Although the study was conducted in maternity hospitals, not all mothers could be included in the study. For example, some mothers did not speak French and were thus not included (less than 5\%). All the tests were carried out in the mother's room and the experimenter was always present during testing.

The mother was first invited to complete the holding/handedness inventory, then the perceptive tasks and finally the CES-D scale. In cases in which the mother had to take care of her newborn, the experimenter helped her to fill the questionnaires when she was holding or feeding her infant. Explanations and goals of the research were provided at the end of the testing. Data on primiparity, the feeding mode, the age of the mother, the gender and the birth weight of the newborn, the term of birth, the mode of delivery were also collected.

\subsection{Data analyses}

Analyses of holding biases are frequently performed in the literature in terms of proportions of left-holders versus right-holders. In accord with previous investigators (e.g., Harris et al., 2001; Turnbull \& Bryson, 2001), we used the holding score as a numerical variable. This choice brings better precision to the behavioral measure than proportions. However, the main disadvantage of using holding scores is associated with large standard deviations. Consequently, to compensate for this statistical effect, we also systematically presented holding biases with the distribution of participants.

\section{Results}

\subsection{Handedness and feeding mode}

Right-handed mothers represented $86 \%$ of the sample. Handedness scores of breastfeeding and bottle-feeding mothers did not significantly differ $(t(98)=-.39, p=.70)$.

\subsection{Perceptive asymmetries}

The left visual field advantages observed for both bottle-feeding mothers $(M=-4.39$, S.D. $=13.90)$ and breastfeeding mothers $(M=-4.66$, S.D. $=13.47)$ were not significantly different $(t(98)=-.10, p=.92)$. Similarly, the left auditory advantages $(M=-10.15$, S.D. $=13.16$ for bottle-feeding mothers and $M=-8.08$, S.D. $=12.20$ for breastfeeding mothers) were not significantly different $(t(98)=.79, p=.43)$.

\subsection{CES-D scores}

The mean score for the CES-D scale was 14.35 (S.D. = 8.22). Thirty-seven percent of the mothers had a score above 16 and $12 \%$ had a score above 22 . This latter score indicates the presence of serious depressive symptoms. The mean 


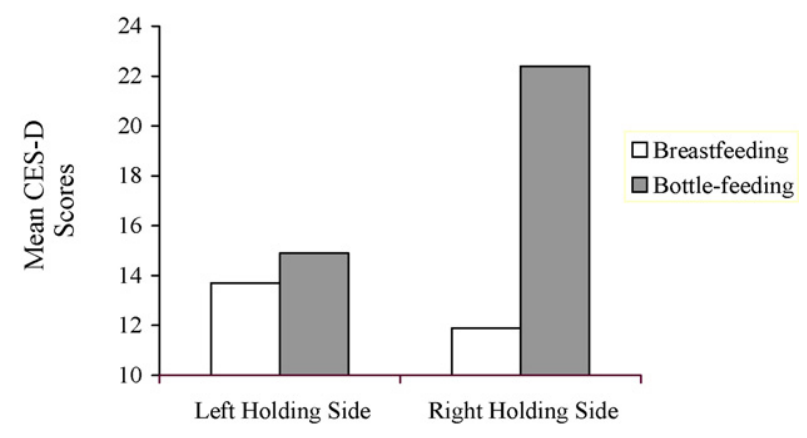

Fig. 2. Mean CES-D scores of breastfeeding and bottle-feeding mothers according to the newborn holding side preference.

CES-D score of breastfeeding mothers $(M=12.9$, S.D. $=7.9)$ was significantly lower $(t(98)=-2.08, p=.04)$ than the mean CES-D score of bottle-feeding mothers $(M=16.4$, S.D. $=8.4)$.

\subsection{Holding side biases}

The mean holding side score for bottle-feeding mothers $(M=-.66$, S.D. $=.65)$ was significantly different from the mean holding side score for breastfeeding mothers $(M=-.21$, S.D. $=.90 ; t(98)=2.72, p<.01)$. We observed that $83 \%$ of bottle-feeding mothers expressed a left-side preference for holding their newborn against $58 \%$ of breastfeeding mothers.

We ran correlational analyses separately for breastfeeding and bottle-feeding mothers. Holding side scores and CES-D scores were correlated only in bottle-feeding mothers $(r(41)=.36, p=.02)$ but not in breastfeeding mothers $(r(59)=-.15, p=.27)$. This means that right-holding is associated to the highest level of depressive symptoms in bottle-feeding mothers (see Fig. 2).

\section{Discussion}

Results showed an effect of the newborn-feeding mode on newborn holding-side biases. In fact, the left-side bias was stronger in bottle-feeding mothers than in breastfeeding mothers. Although the holding behavior measured by the questionnaire did not refer to feeding behavior, it is interesting to note that the feeding postures of the mother had some influence on the general holding side preferences. We can assert that breastfeeding constrained mothers to hold on the right-side. Breastfeeding implies right-holding because the mother must change the feeding breast for physiological reasons. The breastfeeding mother can thus increase her comfort level in holding to the right more often than the bottle-feeding mother. By contrast, bottle-feeding requires the use of a skilled hand and consequently right-handers generally use their right-hand.

Our analyses also demonstrated that the use of bottle-feeding was related to higher level of depressive symptoms compared to the use of breastfeeding. This result was confirmed by previous studies which showed that stress and anxiety levels of bottle-feeding mothers were higher than those of breastfeeding mothers (Heck \& De Castro, 1993; Mezzacappa et al., 2000; Wiesenfeld et al., 1985).

Moreover, depressed mothers chose less often breastfeeding and were less confident in breastfeeding benefits (e.g., Field et al., 2002; Galler et al., 1999). The investigation of the role of breastfeeding on the mental health of the mother is delicate because numerous variables need to be controlled. The present study is not in position to determine why mothers decided to breastfeed or to bottle-feed their newborn. However, results are interpreted with the approach supporting the role of mothers' self-confidence in the breastfeeding decision and supporting an additional role of breastfeeding on mother's self-confidence during breastfeeding period.

Our analyses showed dynamic relations between holding side preferences and levels of depressive symptoms expressed by a significant correlation between the two measures. However, our investigations cannot allow us to conclude to a causal relation between holding side preferences and depression. Further research is needed to determine if mothers expressed more depressive symptoms due to consequences of right-holding or if right-holding (probably 
associated to other variables) led to the emergence of depressive symptoms. We can consider the fact that rightholding preferences could result from a dysfunction of the right hemisphere due to depression, as shown by Jaeger, Borod, and Peselow (1987). In effect, these latter authors showed that depressed patients had weaker left hemispace biases for perceiving emotional chimeric faces compared to non-depressed patients. The fact that we observed no difference neither in visual emotional asymmetries nor in auditory emotional asymmetries between breastfeeding and bottle-feeding mothers ensures that this factor does not explain why right-holding is associated to a higher level of depressive symptoms in bottle-feeding mothers. The present study emphasizes the fact that right-holding must not be systematically associated to depression as it could be understood by overstating the results observed by Weatherill et al. (2004) and Vauclair and Scola (2008). Actually, many breastfeeding mothers hold on the right and not express depressive symptoms. More researches have to be conducted to discover the nature of the link between right-holding and depression.

\section{References}

Bailly, D., Beuscart, R., \& Collinet, C. (1992a). Sex differences in the manifestations of depression in young people: A study of French high school students: I. Prevalence and clinical data. European Child \& Adolescent Psychiatry, 1, 135-145.

Bailly, D., Beuscart, R., \& Collinet, C. (1992b). Sex differences in the manifestations of depression in young people: A study of French high school students: II. Correlates and background factors. European Child \& Adolescent Psychiatry, 1, 146-155.

Beck, A. T., Steer, R. A., \& Brown, G. K. (1996). Manual for the Beck depression inventory-II. San Antonio, TX: Psychological Corporation.

Bogren, L. Y. (1984). Side preference in women and men when holding their newborn child: Psychological background. Acta Psychiatrica Scandinavia, 69, 13-23.

Bourne, V. J., \& Todd, B. K. (2004). When left means right: An explanation of the left cradling bias in terms of right hemisphere specializations. Developmental Science, 7, 19-24.

Bundy, R. S. (1979). Effects of infant head position on sides preference in adult handling. Infant Behavior and Development, 2, 355-358.

De Château, P., \& Andersson, Y. (1976). Left-side preference for holding and carrying newborn infants. II: Doll-holding and carrying from 2 to 16 years. Developmental Medicine and Child Neurology, 18, 738-744.

Donnot, J. (2007). Lateralization of emotion predicts infant holding bias in left-handed students, but not in left-handed mothers. Laterality, 12, $216-226$.

Donnot, J., \& Vauclair, J. (2005). Biais de latéralité dans la façon de porter un très jeune enfant: Une revue de question [Side preferences in infant holding: A review]. Neuropsychiatrie de l'Enfance et de l'Adolescence, 53, 413-425.

Donnot, J., \& Vauclair, J. (2007). Infant holding preferences in maternity hospitals: Testing the hypothesis of the lateralized perception of emotions. Developmental Neuropsychology, 32, 881-890.

Donnot, J., \& Vauclair, J. (in press). Why do we hold infants on the left side? In F. Columbus (Ed.), Family relations: Behavioral, psychological and sociological aspects. Hauppauge, NY: Nova Science Publishers.

Dunn, J. B., \& Richards, M. (1977). Observations on the developing relationship between mother and baby in the neonatal period. In H. R. Schaffer (Ed.), Studies in mother-infant interaction (pp. 427-455). New York: Academic Press.

Erber, N. L., Almerigi, J. B., Carbary, T. J., \& Harris, L. J. (2002). The Contribution of Postural Bias to Lateral Preferences for Holding Human Infants. Brain and Cognition, 48, 352-356.

Earle, S. (2000). Why some women do not breast feed: Bottle feeding and fathers' role. Midwifery, 16, 323-330.

Field, T., Hernandez-Reif, M., \& Feijo, L. (2002). Breastfeeding in depressed mother-infant dyads. Early Child Development and Care, 172, 539-545.

Field, T., Diego, M., \& Hernandez-Reif, M. (2006). Prenatal depression effects on the fetus and newborn: A review. Infant Behavior \& Development, $29,445-455$.

Foster, S. F., Slade, P., \& Wilson, K. (1996). Body image, maternal fetal attachment, and breast feeding. Journal of Psychosomatic Research, 41, 181-184.

Galler, J. R., Harrison, R. H., Biggs, M. A., Ramsey, F., \& Forde, V. (1999). Maternal mood predicts breastfeeding in Barbados. Journal of Developmental and Behavioral Pediatrics, 20, 80-87.

Ginsburg, H. J., Fling, S., Hope, M. L., Musgrove, D., \& Andrews, C. (1979). Maternal holding preferences: A consequence of newborn head-turning response. Child Development, 50, 280-281.

Harris, L. J., \& Fitzgerald, H. E. (1985). Lateral cradling preferences in men and women: Results from a photographic study. The Journal of General Psychology, 112, 185-189.

Harris, L. J., Almerigi, J. B., \& Kirsch, E. A. (2000). Side-preference in adults for holding infants: Contributions of sex and handedness in a test of imagination. Brain and Cognition, 43, 246-252.

Harris, L. J., Almerigi, J. B., Carbary, T. J., \& Fogel, T. G. (2001). Left-side infant holding: A test of the hemispheric arousal-attentional hypothesis. Brain and Cognition, 46, 159-165.

Harris, L. J., Spradlin, M. P., Jr., \& Almerigi, J. B. (2006). Mothers' and fathers' lateral biases for holding their newborn infants: A study of images from the World Wide Web. Laterality, 12, 64-86.

Heck, H., \& De Castro, J. M. (1993). The caloric demand of lactation does not alter spontaneous patterns, nutrient intakes, or moods of women. Physiology and Behavior, 54, 641-648. 
Jaeger, J., Borod, J. C., \& Peselow, E. (1987). Depressed patients have atypical hemispace biases in the perception of emotional chimeric faces. Journal of Abnormal Psychology, 94, 321-324.

Jones, N. A., McFall, B. A., \& Diego, M. A. (2004). Patterns of brain electrical activity in infants of depressed mothers who breastfeed and bottle feed: The mediating role of infant temperament. Biological Psychology, 67, 103-124.

Kuzela, A. L., Stifter, C. A., \& Worobey, J. (1990). Breastfeeding and mother-infant interactions. Journal of Reproductive and Infant Psychology, $8,185-194$.

Manning, J. T., \& Chamberlain, A. T. (1991). Left-side cradling and brain lateralization. Ethology and Sociobiology, 12, $237-244$.

Mezzacappa, E. S., Guethlein, W., Vaz, N., \& Bagiella, E. (2000). A preliminary study of breast-feeding and maternal symptomatology. Annals of Behavioral Medicine, 22, 71-79.

Nubukpo, P., Hartmann, J., \& Clément, J.-P. (2005). Rôle de la personnalité dans la dépression du sujet âgé: Différence entre dépression avec ou sans antécédents [Role of personality in depression of the elderly: Differences between early and late life depression]. Psychologie \& Neuropsychiatrie Du Vieillissement, 3, 63-69.

Oldfield, R. C. (1971). The assessment and analysis of handedness: The Edinburgh Inventory. Neuropsychologia, 9, 97-114.

O'Rourke, N. (2003). Equivalence of French and English language versions of the Center for Epidemiologic Studies-Depression Scale (CES-D) among caregivers of persons with dementia. Canadian Journal on Aging, 22, 323-329.

Radloff, L. S. (1977). The CES-D scale: A self-report depression scale for research in the general population. Applied Psychological Measurement, $1,385-401$.

Reissland, N., Hopkins, B., Helms, P., Williams, B. (in press). Maternal stress and depression and the lateralisation of infant cradling. Journal of Child Psychology \& Psychiatry.

Salk, L. (1960). The effects of the normal heartbeat sound on the behavior of the new-born infant: Implications for mental health. World Mental Health, 12, 168-175.

Suter, S. E., Huggenberger, J., \& Schäehinger, H. (2007). Cold pressor stress reduces left cradling preference in nulliparous human females. Stress, $10,45-51$.

Tamminen, T. (1988). The impact of mother's depression on her nursing experiences and attitudes during breastfeeding. Acta Paediatrica Scandinavica, Supplement, 344, 87-94.

Turnbull, O. H., \& Bryson, H. E. (2001). The leftward cradling bias and hemispheric asymmetry for speech prosody. Laterality, 6, 21-28.

Van der Meer, A., \& Husby, A. (2006). Handedness as a major determinant of functional cradling bias. Laterality, 11, $263-276$.

Vauclair, J., \& Donnot, J. (2005). Infant holding biases and their relations to hemispheric specializations for perceiving facial emotions. Neuropsychologia, 43, 564-571.

Vauclair, J., Scola, C. (2008). Dépression, alexithymie et latéralisation dans la façon de porter un nouveau-né [Infant holding biases in relation to depression, alexithymia and laterality]. Annales Médico-psychologiques, in press.

Weatherill, R. P., Almerigi, J. B., Levendosky, A. A., Bogat, G. A., von Eye, A., \& Harris, L. J. (2004). Is maternal depression related to side of infant holding? International Journal of Behavioral Development, 28, 421-427.

Wiesenfeld, A. R., Malatesta, C. Z., Whitman, P. B., Grangose, C., \& Uili, R. (1985). Psychophysiological response of breast- and bottlefeeding mothers to their infants' signals. Psychophysiology, 22, 79-85. 